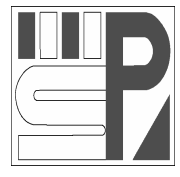

Science Press
Journal of Arid Land

2012, 4(2): 123-131

doi: 10.3724/SP.J.1227.2012.00123

jal.xjegi.com; www.chinasciencejournal.com

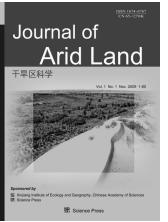

\title{
Simulation of groundwater table dynamics based on Feflow in the Minqin Basin, China
}

\author{
Lan $\mathrm{MA}^{1,2 *}$, XiaoMei $\mathrm{WEI}^{2}$, AnMing $\mathrm{BAO}^{3}$, ShiFei $\mathrm{WANG}^{3}$ \\ ${ }^{1}$ Key Laboratory of Water Sediment Sciences, College of Water Sciences, Beijing Normal University, Beijing 100875, China; \\ ${ }^{2}$ College of Water Resources and Architectural Engineering, Northwest Sci-Tech University of Agriculture and Forestry, Yangling \\ 712100, China; \\ ${ }^{3}$ State Key Laboratory of Desert and Oasis Ecology, Xinjiang Institute of Ecology and Geography, Chinese Academy of Sciences, \\ Urumqi 830011, China
}

\begin{abstract}
As groundwater table declination is an important factor resulting in degradation of eco-environment in the Minqin Basin, China, it is significant to investigate and understand the groundwater table dynamics in this area. According to the physical and geographical conditions of the Minqin Basin, a hydrogeological conceptual model and a mathematical model were established, and the mathematical model was figured out by using Finite Element subsurface Flow system (Feflow). Accurate hydrogeological parameters were acquired, and the spatio-temporal distribution dynamics of groundwater table for 1983-2001 were also simulated. The model performed well with a correlation coefficient of 0.977 and a mean error of $0.9768 \mathrm{~m}$. The inflow and outflow of the groundwater system were predicted by time series analysis, and the groundwater table dynamics for 2011 were further acquired. Generally the groundwater table in the Minqin Basin would continue to decline. The groundwater table would decline during spring and summer irrigation, while it would rise during autumn-winter irrigation. The groundwater depression cones would expand with the increase of center depths. Therefore, regulatory measures should be taken to prevent the declination of groundwater table and improve the eco-environment of this area.
\end{abstract}

Keywords: Feflow; time series analysis; groundwater table dynamics; simulation; prediction

The Shiyang River Basin, particularly the Minqin Ba$\sin$ in the lower reaches, is one of the inland regions with the most vulnerable ecological environments in Northwest China due to water shortage. Groundwater over-exploitation has caused groundwater table to decline remarkably, and resulted in a series of ecological problems such as water quality deterioration, soil ariditization, vegetation deterioration and land desertification (Wei et al., 2005; Ma and Wei, 2006; Sun et al., 2009). The rapid degradation of eco-environment imposes a threat on the sustainable development of the Minqin Basin and even a broader region. Therefore, investigation and understanding of the groundwater dynamics in the Minqin Basin have a great significance in facilitating the restoration of local ecological environment, as well as the sustainable development of water resources and economy in this arid area.
In recent years, the groundwater numerical model Feflow based on finite element method has been widely used to groundwater dynamics simulation due to its modularization, visualization, interaction and diversified solving capabilities (Zhao et al., 2005; Yang and Radulescu, 2006; Russo and Civita, 2009; Dafny et al., 2010; Fujimitsu et al., 2010; Peleg and Gvirtzman, 2010). Some Chinese researchers have simulated the groundwater dynamics in Minqin by Feflow (E, 2005; Huo et al., 2009). Their numerical simulation based on Feflow mainly focused on the simulation of groundwater table when the inputs characteristics such as groundwater boundary conditions, hydrogeological parameters and the inflow and outflow factors had already been known. However, the

Received 2011-09-16; accepted 2012-02-06

*Corresponding author: Lan MA(E-mail: mlpcz@sina.com) 
inflow and outflow factors which are very important to the Feflow model change with time constantly, and the accurate prediction of these parameters tends to have a determinant significance to the credibility of the prediction results of the groundwater dynamics. And the groundwater dynamics prediction will have a more significant guidance to the eco-environment restoration in the Minqin Basin.

This paper presented the development of a hydrogeological conceptual model and a mathematical model for the Minqin Basin, whereby the Feflow numerical model for simulating the groundwater table was also established. The inflow and outflow factors were introduced as random time series so that prediction models can be established and coupled with the numerical models. The dynamic mechanism of groundwater can be rendered, and the stochastic change of model inputs can be reflected in the groundwater table simulation models, by which the temporal and spatial distribution and dynamic proc- ess of groundwater table can be simulated and predicted.

\section{Model construction}

\subsection{Hydrogeological conceptual model}

Figure 1 shows the general location of the Minqin Basin. The boundary of the Minqin Basin groundwater system is determined in accordance to local physical and geographical conditions. The southwest boundary is delineated by the dam base of the Hongyashan Reservoir, the west by the groundwater watershed of the Minqin Basin and the Changning Basin, the north by the front of low and eroded mountain ranges, and the east and southeast by the skirts of the Tengger Desert. All the boundaries are classified as the second-kind boundary. In addition, the rock beneath the Suwu Mountain and the Langpaoquan Mountain is considered as aquifuge, and its regional boundaries are also classified as the second-kind boundary.

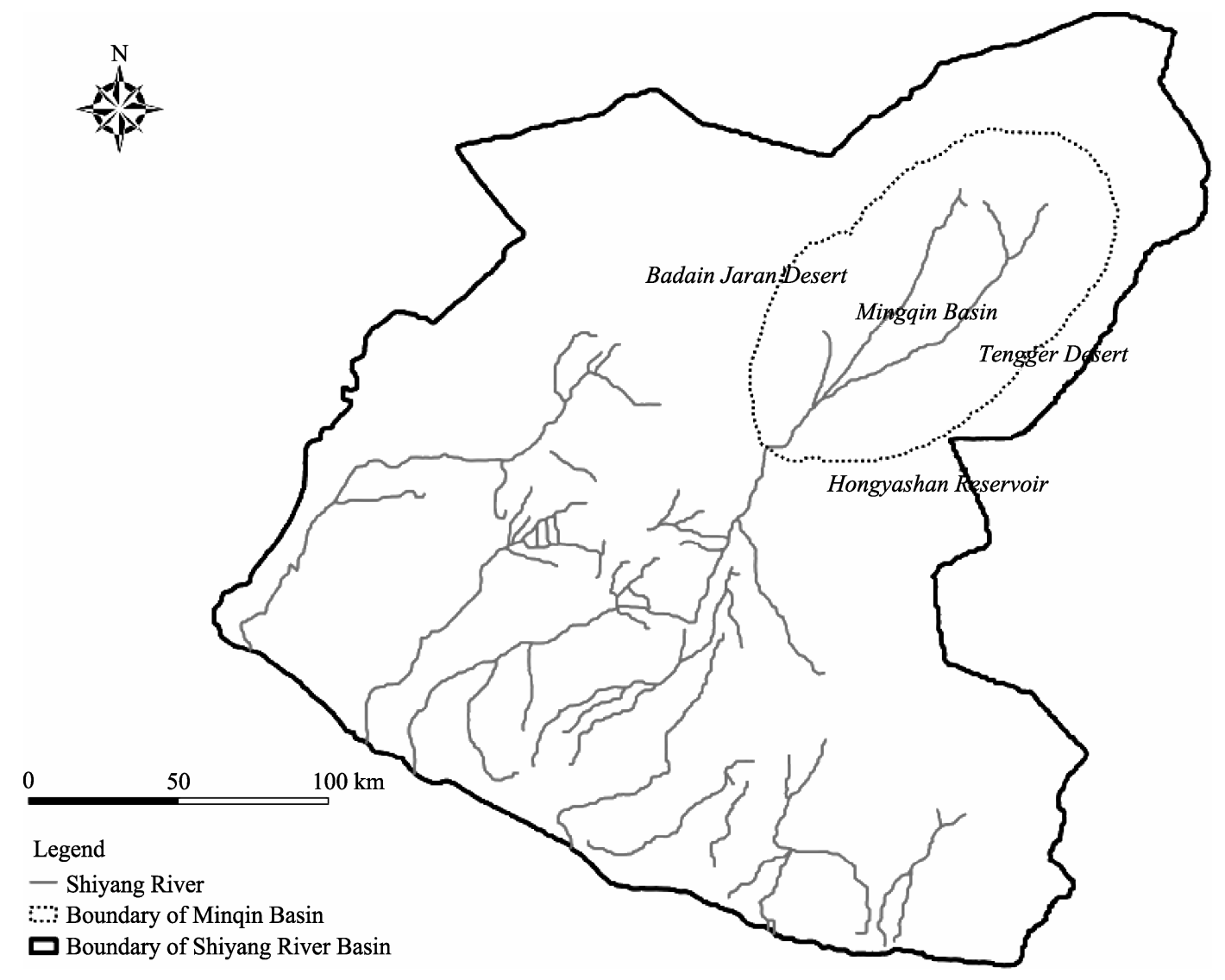

Fig. 1 Location of the Minqin Basin in the Shiyang River Basin 
According to hydrogeological conditions, the upper layer groundwater in the Minqin Basin is classified as phreatic water, and it transits to micro-confined water downwardly to form a phreatic micro-confined water system. The aquifer thickness varies from $150 \mathrm{~m}$ at the south end to $120 \mathrm{~m}$ at the north as hydraulic conductivity decreases. Groundwater flows from southwest to northeast with a hydraulic gradient of $0.3 \%-0.07 \%$ and decreasing runoff intensity (Ma and Wei, 2003). Currently, the groundwater exploitation predominantly involves phreatic water in the depth within $100 \mathrm{~m}$. Therefore, this study mainly focuses on the layer of phreatic water.

The sources of groundwater recharge include seepage recharge from the Hongyashan Reservoir, lateral recharge from the Tengger Desert at the southeast boundary, and infiltration recharge from irrigation, precipitation and coagulation water. The first two are main recharge sources. On the other hand, the discharges mainly consist of evapotranspiration, groundwater pumping and lateral underground runoff flowing out of the basin at the north boundary. Therefore, the study can be generalized as the dynamics simulation of three-dimensional unsteady flow of phreatic water in non-homogeneous anisotropic media.

\subsection{Mathematical model}

\subsubsection{Mathematical expression}

Based on the hydrogeological conceptual model for the Minqin Basin, the mathematical model was established as follows:

$$
\begin{aligned}
& \frac{\partial}{\partial x}\left(K h \frac{\partial H}{\partial x}\right)+\frac{\partial}{\partial y}\left(K h \frac{\partial H}{\partial y}\right)+ \\
& \frac{\partial}{\partial z}\left(K h \frac{\partial H}{\partial z}\right)+\varepsilon=\mu \frac{\partial H}{\partial t}
\end{aligned} ;
$$

initial conditions:

$$
\left.H(x, y, z, t)\right|_{\mathrm{t}=0}=H_{0}(x, y, z),(x, y, z) \in D ;
$$

boundary conditions:

$$
\left.K \frac{\partial H}{\partial n}\right|_{\Gamma_{2}}=q(x, y, z, t),(x, y, z) \in \Gamma_{2}, t \geqslant 0 .
$$

Where, $K$ is permeability coefficient or hydraulic conductivity coefficient $(\mathrm{m} / \mathrm{d}$ ) (due to the lack of experimental data, the aquifer is taken as isotropic); $h$ is the distance from the impervious bed of the aquifer to the free water surface, i.e. aquifer thickness (m); $H$ is water head or water table (m); $\varepsilon$ is the inflow and outflow factors, i.e. the volume of water that vertically flows into or out of the aquifer in unit time and unit area with inflow being positive and outflow being negative $\left(\mathrm{m}^{3} /\left(\mathrm{d} \cdot \mathrm{m}^{2}\right)\right) ; \mu$ is storativity; $t$ is time $(\mathrm{d}) ; H_{0}$ is initial value of water head (m); $D$ is study area enclosed by $\Gamma_{2}$, and $\Gamma_{2}$ is the second kind boundary; $n$ is the direction of outer normal line of the second kind boundary; and $q$ is the volume of water that laterally flows into or out of the aquifer in unit time and unit area on the second-kind boundary $(\mathrm{m} / \mathrm{d})$.

\subsubsection{Initial and boundary conditions}

In this research, relatively complete investigation data of groundwater table from hydrogeological department dated back to 1983 , thus 1983 was taken as the starting year for the numerical simulation of the Minqin Basin groundwater table. The spatial distribution of all observation wells was shown in Fig. 2, and the water tables of the wells were tabulated in Table 1.

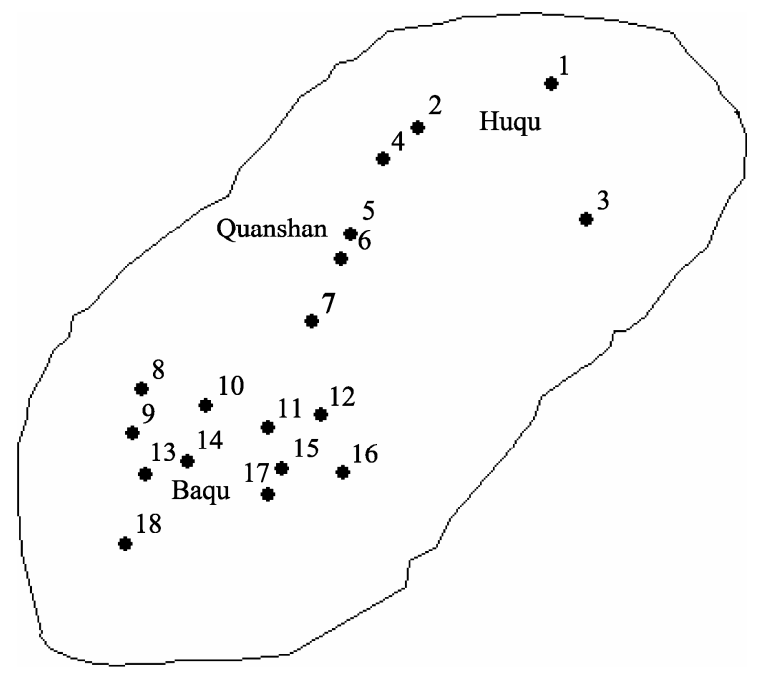

Fig. 2 The distribution of observation wells in the study area; 1-18 means the locations of the 18 wells

Table 1 The initial water tables of observation wells (height above sea level)

\begin{tabular}{cccccc}
\hline Well & $\begin{array}{c}\text { Initial water } \\
\text { table }(\mathrm{m})\end{array}$ & Well & $\begin{array}{c}\text { Initial water } \\
\text { table }(\mathrm{m})\end{array}$ & Well & $\begin{array}{c}\text { Initial water } \\
\text { table }(\mathrm{m})\end{array}$ \\
\hline No.1 & $1,308.34$ & No.7 & $1,338.84$ & No.13 & $1,366.71$ \\
No.2 & $1,312.77$ & No.8 & $1,355.95$ & No.14 & $1,359.81$ \\
No.3 & $1,316.06$ & No.9 & $1,362.07$ & No.15 & $1,353.21$ \\
No.4 & $1,318.07$ & No.10 & $1,354.14$ & No.16 & $1,348.58$ \\
No.5 & $1,324.45$ & No.11 & $1,351.40$ & No.17 & $1,355.06$ \\
No.6 & $1,333.67$ & No.12 & $1,345.88$ & No.18 & $1,377.84$ \\
\hline
\end{tabular}


In this model, all boundaries are defined as the second-kind boundary. The volume of water that laterally flows into or out of the aquifer in unit time and unit area for each boundary was calculated as follows:

$$
q=\frac{Q}{365 l h} .
$$

Where, $q$ is the volume of water that laterally flows into or out of the aquifer in unit time and unit area on the boundary $(\mathrm{m} / \mathrm{d})$ (due to the short simulation duration, this variable is assumed to be a constant for each boundary); $l$ is the length of the boundary (m); $h$ is the distance from the impervious bed of the aquifer to the free water surface, i.e. aquifer thickness (m); and $Q$ is flow volume $\left(\mathrm{m}^{3} / \mathrm{a}\right)$.

Five boundaries were separated to effectively describe the flow volume $Q$ in the Minqin Basin (Fig. 3).

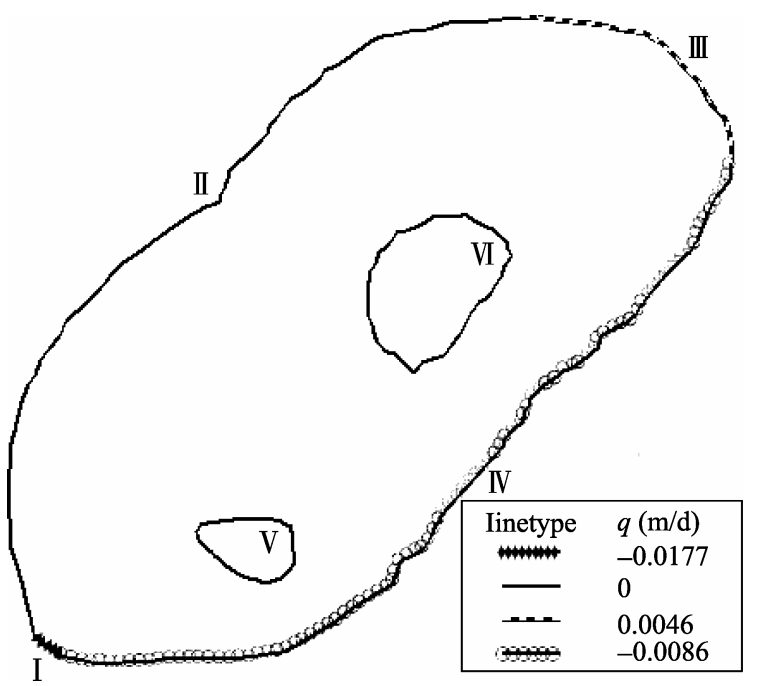

Fig. 3 The flow boundaries and $q$ (positive value indicates "out" and negative value indicates "in")

For boundary I, the flow volume was taken as the amount of seepage from the Hongyashan Reservoir, usually averaged at about $0.060 \times 10^{8} \mathrm{~m}^{3} / \mathrm{a}$ (E, 2005). For boundary III, the flow volume was taken as the lateral groundwater discharge, usually averaged at about $0.073 \times 10^{8} \mathrm{~m}^{3} / \mathrm{a}$ (E, 2005). For boundary IV, the lateral recharge from the southeast desert was evaluated to be $0.466 \times 10^{8} \mathrm{~m}^{3} / \mathrm{a}$ according to published literature (Ma et al., 2002; Wei, 2004). The boundaries of II, V (rock boundary beneath the Suwu Mountain) and VI (rock boundary beneath the Langpaoquan Mountain) were determined as no-flow boundary ac- cording to their characteristics (E, 2005).

The calculation results of the volume of water that laterally flows into or out of the aquifer in unit time and unit area on each boundary were shown in Fig. 3.

\subsubsection{Hydrogeological parameters}

Groundwater system in the Minqin Basin is generalized as three-dimensional unsteady flow of phreatic water in non-homogeneous anisotropic media. In Huqu, north of the basin, there are mainly alluvial and lacustrine strata, and associated soils are hoar and green-gray clay sand and sand soils. The strata in the south and at the banks of the Shiyang River are mainly alluvial, and associated soils are clay sand and sand soils. The lithology generally changes from coarseness to fineness from southwest to northeast. Based on field investigation, hydrogeological documents and literature (E, 2005), the basin was divided into 24 subareas according to their hydrogeological parameters (conductivity and storativity) (Fig. 4). Initial values of conductivity and storativity were given in Table 2 .

1.2.4 Inflow and outflow factors

The effective precipitation in the Minqin Basin is only 79.5-102 $\mathrm{mm}$ per year and the groundwater depths are more than $5 \mathrm{~m}$ below the ground surface. Generally, infiltration recharge of precipitation and coagulation water and evaporation of phreatic water has little influence on groundwater. Inflow and outflow factors mainly take into account infiltration recharge from irrigation, exploitation and evapotranspiration.

For cropland groundwater system, there were

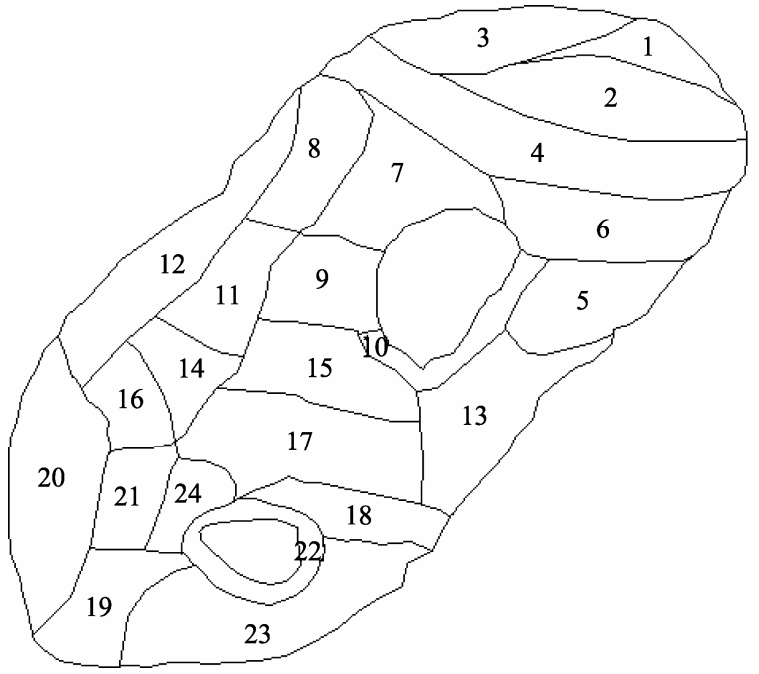

Fig. 4 Subarea division based on hydrogeological parameters 
Table 2 Initial values of conductivity and storativity

\begin{tabular}{cccccc}
\hline Subarea & $\begin{array}{c}\text { Conductivity } \\
(\mathrm{m} / \mathrm{d})\end{array}$ & Storativity & Subarea & $\begin{array}{c}\text { Conductivity } \\
(\mathrm{m} / \mathrm{d})\end{array}$ & Storativity \\
\hline 1 & 1.10 & 0.076 & 13 & 5.77 & 0.127 \\
2 & 1.92 & 0.070 & 14 & 9.07 & 0.153 \\
3 & 2.45 & 0.074 & 15 & 9.14 & 0.130 \\
4 & 2.07 & 0.068 & 16 & 10.23 & 0.130 \\
5 & 4.00 & 0.110 & 17 & 10.97 & 0.148 \\
6 & 4.00 & 0.080 & 18 & 12.07 & 0.146 \\
7 & 4.10 & 0.079 & 19 & 13.71 & 0.180 \\
8 & 4.75 & 0.090 & 20 & 13.25 & 0.165 \\
9 & 4.74 & 0.117 & 21 & 13.43 & 0.173 \\
10 & 4.00 & 0.110 & 22 & 5.10 & 0.143 \\
11 & 6.79 & 0.126 & 23 & 9.99 & 0.171 \\
12 & 9.14 & 0.130 & 24 & 12.56 & 0.174 \\
\hline
\end{tabular}

three annual irrigation events that generally occurred in spring, summer and autumn-winter. The simulation time series (1983-2001) was divided into 115 time segments according to irrigation or non-irrigation season. The inflow and outflow factors for every time segment were calculated.

Due to the difficulty in separately calculating the infiltration recharge from canal systems and farmlands, comprehensive utilization coefficients of canal systems, well systems and farmland water were taken into account (Chen and $\mathrm{Qu}, 1992$ ). The infiltration recharges of canal irrigation and well irrigation were calculated respectively:

(1) Infiltration recharges from canals in canal irrigation systems during a certain period of time:

$$
W_{s q}=W_{s} \times\left(1-\eta_{s q}\right),
$$

where, $W_{s q}$ is infiltration recharges from canals in canal irrigation systems $\left(10^{4} \mathrm{~m}^{3}\right) ; W_{s}$ is outflow volume of the Honyashan Reservoir $\left(10^{4} \mathrm{~m}^{3}\right)$; and $\eta_{s q}$ is utilization coefficient of the canal systems in canal irrigation, $\eta_{s q}=0.5$.

(2) Infiltration recharges from farmlands in canal irrigation systems during a certain period of time:

$$
W_{s t}=W_{s} \times \eta_{s q} \times\left(1-\eta_{t}\right),
$$

where, $W_{s t}$ is infiltration recharges from farmlands in canal irrigation systems $\left(10^{4} \mathrm{~m}^{3}\right)$; and $\eta_{t}$ is utilization coefficient of farmland water, $\eta_{t}=0.7$.

(3) Infiltration recharges from canals in well irrigation systems during a certain period of time:

$$
W_{g q}=W_{g} \times\left(1-\eta_{g q}\right),
$$

where, $W_{g q}$ is infiltration recharges from canals in well irrigation systems $\left(10^{4} \mathrm{~m}^{3}\right)$; $W_{g}$ is volume of groundwater exploitation in well irrigation systems $\left(10^{4} \mathrm{~m}^{3}\right)$; and $\eta_{g q}$ is utilization coefficient of the canal systems in well irrigation, $\eta_{g q}=0.65$.

(4) Infiltration recharges from farmlands in well irrigation systems during a certain period of time:

$$
W_{g t}=W_{g} \times \eta_{g q} \times\left(1-\eta_{t}\right),
$$

where, $W_{g t}$ is infiltration recharges from farmlands in well irrigation systems $\left(10^{4} \mathrm{~m}^{3}\right)$.

(5) Inflow and outflow factors of cropland groundwater system during a certain period of time:

$$
q_{1}=\frac{W_{s q}+W_{s t}+W_{g q}+W_{g t}-W_{g z}}{A \times t_{1}} .
$$

Where, $q_{1}$ is the sum of inflow and outflow factors of cropland groundwater system, i.e. the sum of groundwater recharge and discharge in unit time and unit area for one irrigation event $\left(10^{-4} \mathrm{~m} / \mathrm{d}\right)$, with positive value indicating recharge and negative value indicating discharge; $A$ is total area of irrigation $\left(10^{4} \mathrm{hm}^{2}\right) ; t_{1}$ is irrigation duration (d); and $W_{g z}$ is total volume of groundwater exploitation $\left(10^{4} \mathrm{~m}^{3}\right)$.

Groundwater loss due to woodland evapotranspiration in the Minqin Basin was estimated as $308 \mathrm{~mm}$ annually. This loss was distributed from April to Oc-

\begin{tabular}{|c|c|c|c|c|c|c|c|c|}
\hline & \multicolumn{7}{|c|}{ Month } & \multirow{2}{*}{ Total } \\
\hline & Apr & May & Jun & Jul & Aug & Sep & Oct & \\
\hline Loss (mm) & 0.62 & 14.78 & 57.29 & 126.59 & 56.36 & 48.36 & 4.31 & 308.31 \\
\hline $\begin{array}{c}\text { Percentage } \\
(\%)\end{array}$ & 0.2 & 4.8 & 18.6 & 41.1 & 18.3 & 15.7 & 1.4 & 100 \\
\hline
\end{tabular}
tober according to the evapotranspiration intensity of woodlands (Table 3 ).

Table 3 The annual distribution of groundwater loss caused by woodland evapotranspiration

The study period (1983-2001) was divided into 228 time segments according to calendar month to calculate the inflow and outflow factors of the woodland groundwater system, as follows:

$$
q_{2}=\frac{W}{t_{2}} \times 10 .
$$

Where, $q_{2}$ is woodland groundwater discharge in a month $\left(10^{-4} \mathrm{~m} / \mathrm{d}\right) ; W$ is loss of groundwater due to woodland evapotranspiration $(\mathrm{mm})$ in a month (Table 3 ); and $t_{2}$ is time (d) which is the number of days in a month. 


\section{Solutions of mathematical model}

Feflow was used to figure out the above mathematical model. The main processes include the construction of 2D and 3D models, time step setting (automatic time step, and the initial time step appointed $0.001 \mathrm{~d}$ ), initial and boundary conditions of flow, hydraulic conductivities, storativity and inflow and outflow factors. According to terrain characteristics, the study area was discretized by a finite element mesh with 18,603 triangles (Fig. 5). The inflow and outflow factors were primarily related to croplands and woodlands (Fig. 6).

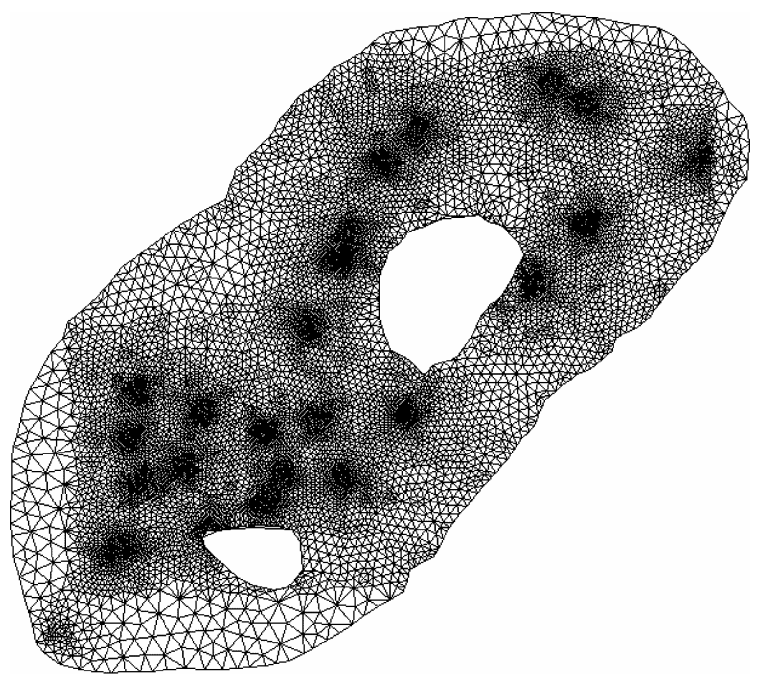

Fig. 5 The finite element mesh discretization results

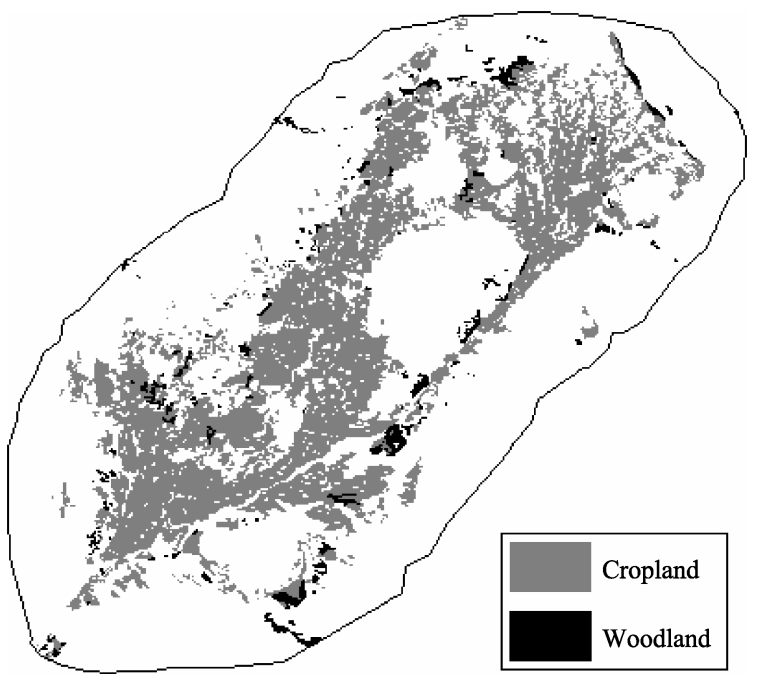

Fig. 6 The distribution of croplands and woodlands

Hydraulic conductivity and storativity of the aquifer were calibrated by model running. The errors were expressed as follows:

$$
R M S E=\sqrt{\frac{1}{n} \sum_{i=1}^{n}\left(H_{i}-H_{i}^{\prime}\right)^{2}} .
$$

Where, RMSE is root mean square error $(\mathrm{m}) ; n$ is total number of measurements; $H_{i}$ is simulated value of groundwater table at the end of $i^{\text {th }}$ month (m); and $H_{i}^{\prime}$ is observed value of groundwater table at the end of $i^{\text {th }}$ month $(\mathrm{m})$.

The root mean square errors of the observed and simulated values for each well in the period of 1983-2001 were shown in Table 4. Calibrated values of hydraulic conductivity and storativity were provided in Table 5.

There was a correlation coefficient of 0.9771 between the simulated and observed values with a mean error of $0.9768 \mathrm{~m}$. This indicates that the model construction, solution and parameters setting match the real situation. The observation wells No. 1, No. 5 and No. 18 were chosen to represent the three irrigation areas of Huqu, Quanshan and Baqu. The change of observed and simulated values of the groundwater table for the three observation wells was shown in Figs. 7a-c.

Generally, the groundwater tables of the three wells had a clearly decreasing trend with a decreasing range of about $10 \mathrm{~m}$ in 1983-2001. The well No. 5 for Quanshan irrigation area had a greater annual changing range of over $2 \mathrm{~m}$ compared to the wells No. 1 and No. 18 (Figs. 7a-c).

Table 4 Root mean square error (RMSE) of the observed and simulated values from Feflow

\begin{tabular}{cccccc}
\hline Well & $R M S E(\mathrm{~m})$ & Well & RMSE $(\mathrm{m})$ & Well & $R M S E(\mathrm{~m})$ \\
\hline No.1 & 0.8164 & No.7 & 0.8431 & No.13 & 2.1882 \\
No.2 & 1.1205 & No.8 & 1.4873 & No.14 & 1.2193 \\
No.3 & 1.3936 & No.9 & 1.3425 & No.15 & 0.7062 \\
No.4 & 1.0072 & No.10 & 1.0740 & No.16 & 0.8213 \\
No.5 & 1.6308 & No.11 & 1.2599 & No.17 & 1.0312 \\
No.6 & 0.8372 & No.12 & 1.1943 & No.18 & 0.7160 \\
\hline
\end{tabular}

Table 5 Calibrated values of conductivity and storativity

\begin{tabular}{cccccc}
\hline Subarea & $\begin{array}{c}\text { Conductivity } \\
(\mathrm{m} / \mathrm{d})\end{array}$ & Storativity & Subarea & $\begin{array}{c}\text { Conductivity } \\
(\mathrm{m} / \mathrm{d})\end{array}$ & Storativity \\
\hline 1 & 2.10 & 0.10 & 13 & 6.77 & 0.12 \\
2 & 2.92 & 0.11 & 14 & 9.07 & 0.11 \\
3 & 3.45 & 0.10 & 15 & 9.14 & 0.12 \\
4 & 3.07 & 0.08 & 16 & 12.23 & 0.13 \\
5 & 6.00 & 0.12 & 17 & 12.97 & 0.11 \\
6 & 10.00 & 0.11 & 18 & 10.07 & 0.13 \\
7 & 4.10 & 0.09 & 19 & 13.71 & 0.14 \\
8 & 4.75 & 0.09 & 20 & 13.25 & 0.14 \\
9 & 6.75 & 0.10 & 21 & 15.43 & 0.16 \\
10 & 4.00 & 0.11 & 22 & 6.50 & 0.12 \\
11 & 7.00 & 0.12 & 23 & 9.90 & 0.14 \\
12 & 9.14 & 0.12 & 24 & 9.00 & 0.14 \\
\hline
\end{tabular}



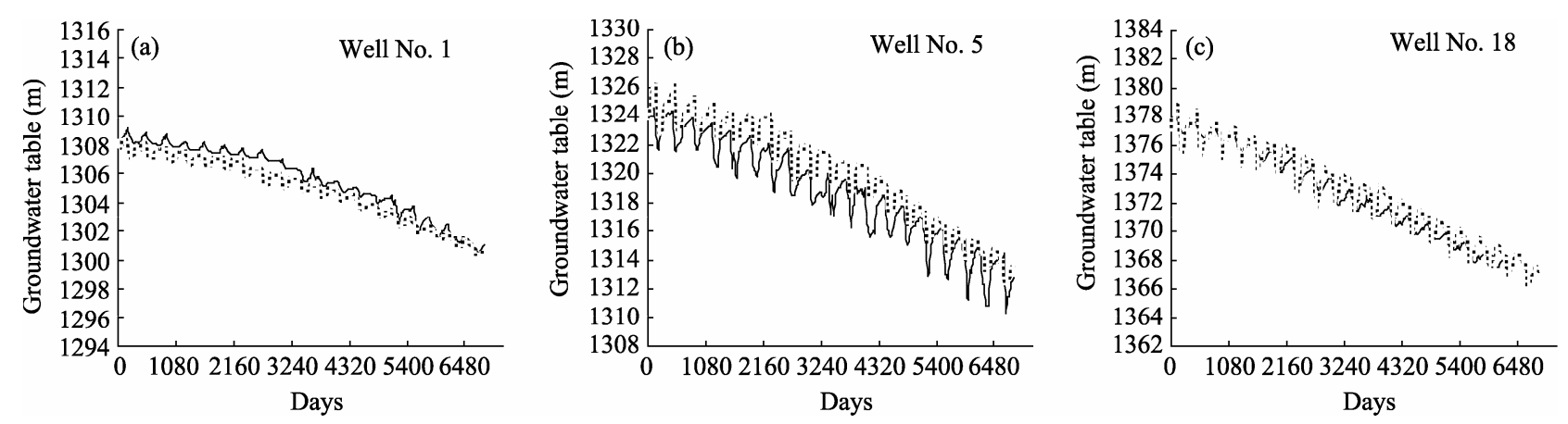

Fig. 7 Comparison between the observed and simulated values from Feflow. Real and dashed lines respectively indicate observed and simulated values.

\section{Predictions of groundwater table dynamics}

\subsection{Prediction of inflow and outflow factors}

The boundary conditions and hydrogeological parameters were assumed to be constant due to their small differences during the study period. The inflow and outflow factors which were largely influenced by human activities and climate condition played an important role in predicting groundwater dynamics. The year 2011 was chosen for the prediction.

Inflow and outflow factors of the woodland groundwater system were also calculated using the above-mentioned method due to their small differences within the study period. This study mainly considered the prediction of inflow and outflow factors of cropland groundwater system which mainly consist of infiltration recharge from canal systems, farmlands and total volume of groundwater exploitation. Although these processes have different mechanisms, they will change stochastically under the influences of various factors, if the current way of water resources utilization could not be changed, or in other words, if any special control could not be taken over these inflow and outflow factors. Therefore, time series analysis was adopted to conduct the prediction. The prediction was based on the inflow and outflow factors of the cropland groundwater system $q_{1}$ for the time period from 1983 to 2001.

There were almost the same time intervals between the three yearly irrigation events in the Minqin Basin. Each irrigation event was counted as one time segment, and the inflow and outflow factors of the cropland groundwater system after 2001 were predicted using time series analysis. The combined equation $x_{t}=p_{t}+r_{t}$ was obtained through fitting trend terms, periodic terms and stochastic terms:

(1) The periodic equation could be fitted as follows: $p_{t}=74.40771 \mathrm{e}^{-0.00505 \mathrm{t}} \sin \left(2 \pi\left\|\frac{t}{3}\right\|^{4.04012}+2.792182\right)$,

(2) Auto-regressive and moving average model could be expressed by ARMA $(3,3)$ :

$$
\begin{aligned}
& r_{t}=-0.2993+0.007149 r_{t-1}+ \\
& 0.361416 r_{t-2}+0.275263 r_{t-3}+ \\
& 0.285401 \mathrm{e}_{t-1}+0.877837 \mathrm{e}_{t-2}-0.829925 \mathrm{e}_{t-3}+\mathrm{e}_{t} .
\end{aligned}
$$

(3) Verification of model parameters and prediction Residual square sum, residual standard deviation, AIC, correlation coefficient, and degree of fit were 846.2452, $4.2891,14.2775,0.994$ and $98.79 \%$, respectively. The predicted values of groundwater inflow and outflow factors of the croplands for 2002-2011 were shown in Table 6.

Table 6 The predicted values of groundwater inflow or outflow factors of croplands $\left(10^{-4} \mathrm{~m} / \mathrm{d}\right)$

\begin{tabular}{cccc}
\hline Year & Spring irrigation & Summer irrigation & Autumn-winter irrigation \\
\hline 2002 & -10.8639 & -47.3310 & 21.7389 \\
2003 & -5.3843 & -47.1465 & 21.9306 \\
2004 & -4.0314 & -46.3904 & 22.1990 \\
2005 & -3.6039 & -45.4653 & 22.1595 \\
2006 & -3.3690 & -44.6157 & 21.9692 \\
2007 & -3.2121 & -43.8510 & 21.7126 \\
2008 & -3.1047 & -43.1430 & 21.4236 \\
2009 & -3.0285 & -42.4714 & 21.1180 \\
2010 & -2.9711 & -41.8247 & 20.8048 \\
2011 & -2.9012 & -41.1616 & 20.4964 \\
\hline
\end{tabular}

In the Minqin Basin, spring and summer irrigation needed to consume a larger amount of water during 
the crop growth period. Groundwater exploitation volume was large, so groundwater was in the discharge period during spring and summer irrigation. Nevertheless, spring irrigation partially consumed surface water from the Hongyashan Reservoir, so absolute values of inflow and outflow factors of the groundwater system for spring irrigation were smaller compared to those for summer irrigation. Autumnwinter irrigation consumed less water, and surface water was the main source for irrigation. There was greater infiltration recharge in canal irrigation systems, and less groundwater exploitation in autumn-winter irrigation period, so the inflow and outflow factors of groundwater were positive and groundwater was in its recharge period.

\subsection{Prediction of groundwater table dynamics}

The inflow and outflow factors predicted from the time series analysis were inputted into the established Feflow model, and groundwater tables for the observation wells during 2002-2011 were predicted.
Groundwater table dynamics in 2011 for the three typical wells No. 1, No. 5 and No. 18 representing Huqu, Quanshan and Baqu irrigation areas, respectively, were illustrated (Figs. 8a-c). Meanwhile, according to the ground elevation of each observation well, the spatial distribution of groundwater depth at the end of 2011 was obtained (Fig. 9).

The groundwater table in the Minqin Basin will continue to decline in the near future, and it has a declining trend in the irrigation period as well as a restoration trend in the non-irrigation period (Figs. 7, 8). As of 2011, the groundwater depth in the Minqin Basin is expected to increase to $20.5-37.8 \mathrm{~m}$ (Fig. 9). Meanwhile, with the over-exploitation of groundwater, there apparently exists a groundwater depression cone in Baqu irrigation area in the south of the basin, and its center depth will reach up to $40 \mathrm{~m}$. Therefore, it is necessary that some effective measures, such as water saving, water consumption controlling and water transfer from the other river basins, be taken to prevent the groundwater table from further decline.
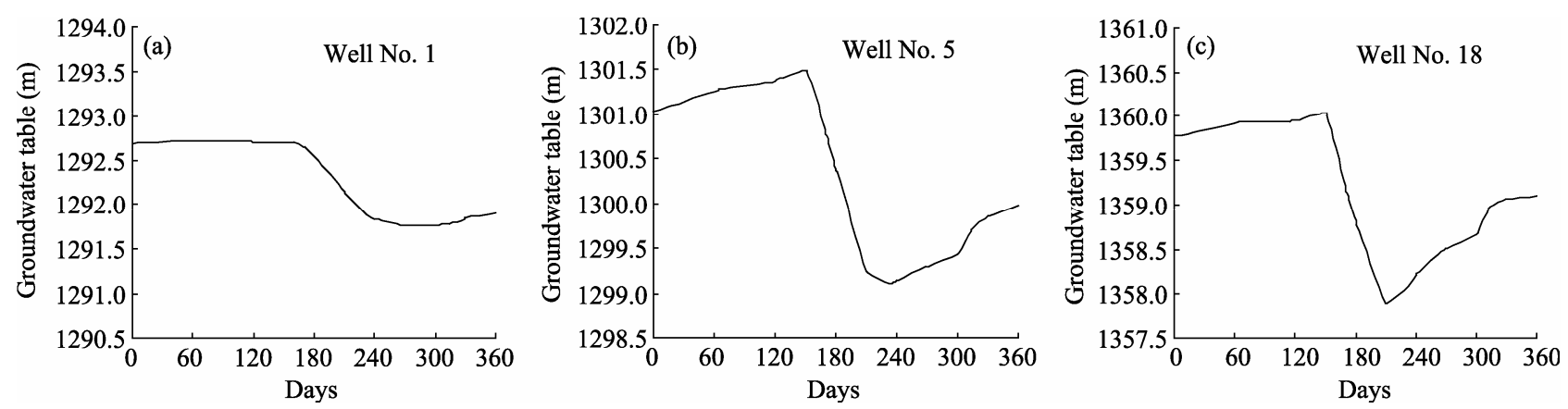

Fig. 8 The groundwater table dynamics in 2011

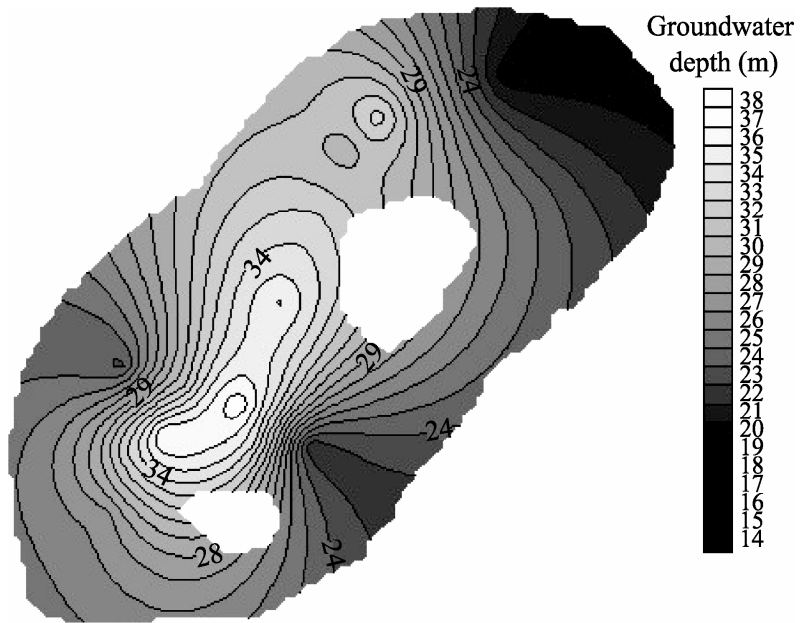

Fig. 9 The spatial distribution of groundwater depth $(\mathrm{m})$ at the end of 2011

\section{Conclusions}

Based on field investigation, data collection and analysis, the hydrogeological conceptual model and mathematical model for the groundwater table dynamics in the Minqin Basin were established. The mathematical model was figured out using the Feflow software, and there was a relatively high accuracy with a correlation coefficient of 0.977 and an absolute error of less than $1 \mathrm{~m}$. Meanwhile, more accurate hydrogeological parameters for the Minqin Basin were acquired. The inflow and outflow of the cropland groundwater system were predicted through time series analysis, and the groundwater table dynamics in 2011 were also obtained using the established Feflow 
model. In general, the groundwater table in the Minqin Basin will continue to decline. The seasonal change of the water table appear to decline during spring and summer irrigation, while recover to some extent during autumn-winter irrigation. The groundwater depression cone will expand with the increase of center depth. The groundwater table dynamics prediction method based on Feflow-time series analysis can not only predict future groundwater table levels, but also effectively resolve the difficulty in determining inflow

\section{References}

Chen L H, Qu Y G. 1992. Reasonable Exploitation and Utilization of Water Resources and Land Resources in Hexi Region. Beijing: Science Press.

Dafny E, Burg A, Gvirtzman H. 2010. Effects of Karst and geological structure on groundwater flow: the case of Yarqon-Taninim Aquifer, Israel. Journal of Hydrology, 389(3-4): 260-275.

E Y H. 2005. GIS-assisted modeling of groundwater spatial and temporal variations in groundwater levels and its influence on ecoenvironmental change process in Minqin Basin, Northwest China. Ph.D. Thesis, Lanzhou: Lanzhou University.

Fujimitsu Y, Fukuoka K, Ehara S, et al. 2010. Evaluation of subsurface thermal environmental change caused by a ground-coupled heat pump system. Current Applied Physics, 10(2): S113-S116.

Huo Z L, Feng S Y, Kang S Z, et al. 2009. Application of ANN and FEFLOW model to simulate groundwater level variation in arid inland area. Journal of Hydraulic Engineering, 40(6): 724-728.

Ma J Z, Wei H. 2003. The ecological and environmental problems caused by the excessive exploitation and utilization of groundwater resources in the Minqin Basin, Gansu province. Arid Zone Research, 20(4): 261-265.

Ma L, Wei X M. 2006. Analysis on aberrance point of annual runoff serials in the downstream of Shiyang River. Agricultural Research in the Arid Areas, 24(2): 174-177.

Ma X W, Li B G, Wu C R. 2002. Modeling the influence of land use on and outflow factors of groundwater system in areas with a shortage of data.

\section{Acknowledgments}

This work was funded by the National Natural Science Foundation of China (50879071 and 40801103) and the Ph.D. Programs Foundation of the Ministry of Education of China (200800271029). The authors would like to express deep gratitude to the anonymous reviewers for their valuable suggestions that greatly improved the manuscript.

groundwater in oasis: the case of Minqin Oasis. Resources Science, 24(2): 49-55.

Peleg N, Gvirtzman H. 2010. Groundwater flow modeling of two-levels perched karstic leaking aquifers as a tool for estimating recharge and hydraulic parameters. Journal of Hydrology, 388(1-2): 13-27.

Russo S L, Civita M V. 2009. Open-loop groundwater heat pumps development for large buildings: a case study. Geothermics, 38(3): 335-345.

Sun Y, Kang S Z, Li F S, et al. 2009. Comparison of interpolation methods for depth to groundwater and its temporal and spatial variations in the Minqin oasis of Northwest China. Environmental Modelling and Software, 24(10): 1163-1170.

Wei H. 2004. Study of water resources carrying capacity in Minqin Basin. MSc Thesis, Lanzhou: Lanzhou University.

Wei X M, Kang S Z, Su X L, et al. 2005. Impact of oasis agricultural development on the transforming relationship between surface water and groundwater in the Shiyang River Basin. Transactions of the Chinese Society of Agricultural Engineering, 21(5): 38-41.

Yang J W, Radulescu M. 2006. Paleo-fluid flow and heat transport at 1575 Ma over an E-W section in the Northern Lawn Hill Platform, Australia: Theoretical results from finite element modeling. Journal of Geochemical Exploration, 89(1-3): 445-449.

Zhao C Y, Wang Y C, Chen X, et al. 2005. Simulation of the effects of groundwater level on vegetation change by combining FEFLOW software. Ecological Modelling, 187(2-3): 341-351. 